\title{
Autism and visual agnosia in a child with right occipital lobectomy
}

\author{
I Jambaqué, L Mottron, G Ponsot, C Chiron
}

Hôpital Saint Vincent de Paul, Service de Neuropédiatrie, Université René Descartes, Paris, France

I Jambaqué

G Ponsot

Clinique Spécialisée de l'Autisme, Hôpital Rivière des Prairies et Département de Psychiatrie de l'Université de Montréal, Canada

L Mottron

Hôpital Fréderic Joliot, Département de Recherche Médicale du Centre à l'Energie Atomique et Inserm U 29, Orsay, France C Chiron

Correspondence to: Dr Isabelle Jambaqué, Hôpital Saint Vincent de Paul, Service de

Neuropédiatrie, 82 Avenue Denfert Rochereau, 75674 Paris, Cedex 14, France. Telephone 00331404880 48; fax 00330140488340 .

Received 23 June 1997 and in final revised form 6 March 1998

Accepted 6 March 1998

\begin{abstract}
Objectives-Autistic disorder is a developmental handicap with an unknown neurological basis. Current neuropsychological models for autism suggest an abnormal construction of visual perceptual representation or a deficit in executive functions. These models predict cerebral lesions in the temporo-occipital or frontal regions of autistic patients. The present study aimed at studying the presence of symptoms of autism and visual agnosia in a 13 year old girl who had a right temporo-occipital cortical dysplasia that was surgically removed at the age of 7.

Methods-Neuropsychological evaluation included Wechsler and Kaufman intelligence scales, a test of word fluency, digit span, Corsi block, California verbal learning, Trail making, Benton facial recognition, Snoodgrass object recognition tests, Rivermead face learning subtest, and developmental test of visual perception. The ADI-R was used to show current and retrospective diagnosis of autistic disorder. Neuroimagery included brain MRI, single photon emission computed tomography (SPECT), and PET.

Results-Brain MRI showed a right occipital defect and an abnormal hyperintensity of the right temporal cortex. PET and SPECT disclosed a left frontal hypometabolism together with the right occipital defect. Neuropsychological testing showed a visual apperceptive agnosia and executive function deficits. Psychiatric study confirmed the diagnosis of autistic disorder.

Conclusions-Although the possibilty that autism and visual agnosia were dissociable factors in this patient cannot be excluded, the finding of both deficits supports the possibility that occipitotemporal lesions can predispose to the development of autism.

(F Neurol Neurosurg Psychiatry 1998;65:555-560)
\end{abstract}

Keywords: autism; visual agnosia; executive deficit; child

Autism is a developmental syndrome characterised by a triad of behavioural impairments in the areas of social relationships, communication, and repetitive behaviours or restricted interests. Early models of cognitive abnormalities in autism focused mainly on language deficits, ${ }^{1}$ as many persons with autism present significant language delays or absence of language. However, these models failed to account for those "high functioning" persons with autism whose level of verbal production is average or above average. Deficits in the social and communication area have convincingly been attributed to an impairment in the ability to interpret people's intentions, beliefs, and desires, known as "theory of mind". ${ }^{2}$ Nevertheless, symptoms of the "repetitive behaviours and restricted interest" area are difficult to explain through a "theory of mind" deficit, and an "executive functions deficit" might be a more appropriate candidate to explain this cluster of symptoms. ${ }^{3}$ Recently, it has been proposed that abnormal perceptual representations of objects and faces might account for the social impairments, repetitive behaviours, and restricted interests that are commonly seen in persons with autism. ${ }^{4}$ At a cognitive level, persons with autism present an atypical processing of complex visual figures, including an impairment of movement perception, ${ }^{5}$ a deficit in facial perception, ${ }^{6-8}$ and atypical part-whole integration of visual stimuli. ${ }^{9}{ }^{10}$

Clinical arguments in favour of a visual perceptual impairment in the aetiology of autistic disorder originate from the occasional finding of comorbidity of autism and various visual deficits. ${ }^{11}$ A pattern of autistic-like behavioural symptoms has long been recognised in infants with retrolental fibroplasia sequelae. ${ }^{13}$ Children with delayed visual maturation may exhibit transient autistic behaviour. ${ }^{14}{ }^{15}$ Central visual disturbances also contribute largely to the autistic picture seen in children who develop infantile spasms. ${ }^{16}$ Futhermore, several cases of prosopagnosia in childhood suggest an association between autism and developmental visual agnosia ${ }^{17-20}$ although some cases are clearly non-autistic. ${ }^{21-23}$ The present paper discusses the case of a 13 year old girl with autistic disorder and developmental apperceptive visual agnosia due to right occipitotemporal damage, whose neurofunctional imaging disclosed a left frontal hypometabolism in addition to the right occipitotemporal defect.

\section{Case report}

MEDICAL HISTORY

This right handed girl, now aged 13, was born at term after normal vaginal delivery. There was no family history of neurological or psychiatric disorder. At 1 month, the child developed daily partial seizures which became rapidly intractable to all anticonvulsive drugs. Seizures were characterised at one month by left down deviation of her eyes, oculoclonies, and raising of her arms with cyanosis and 

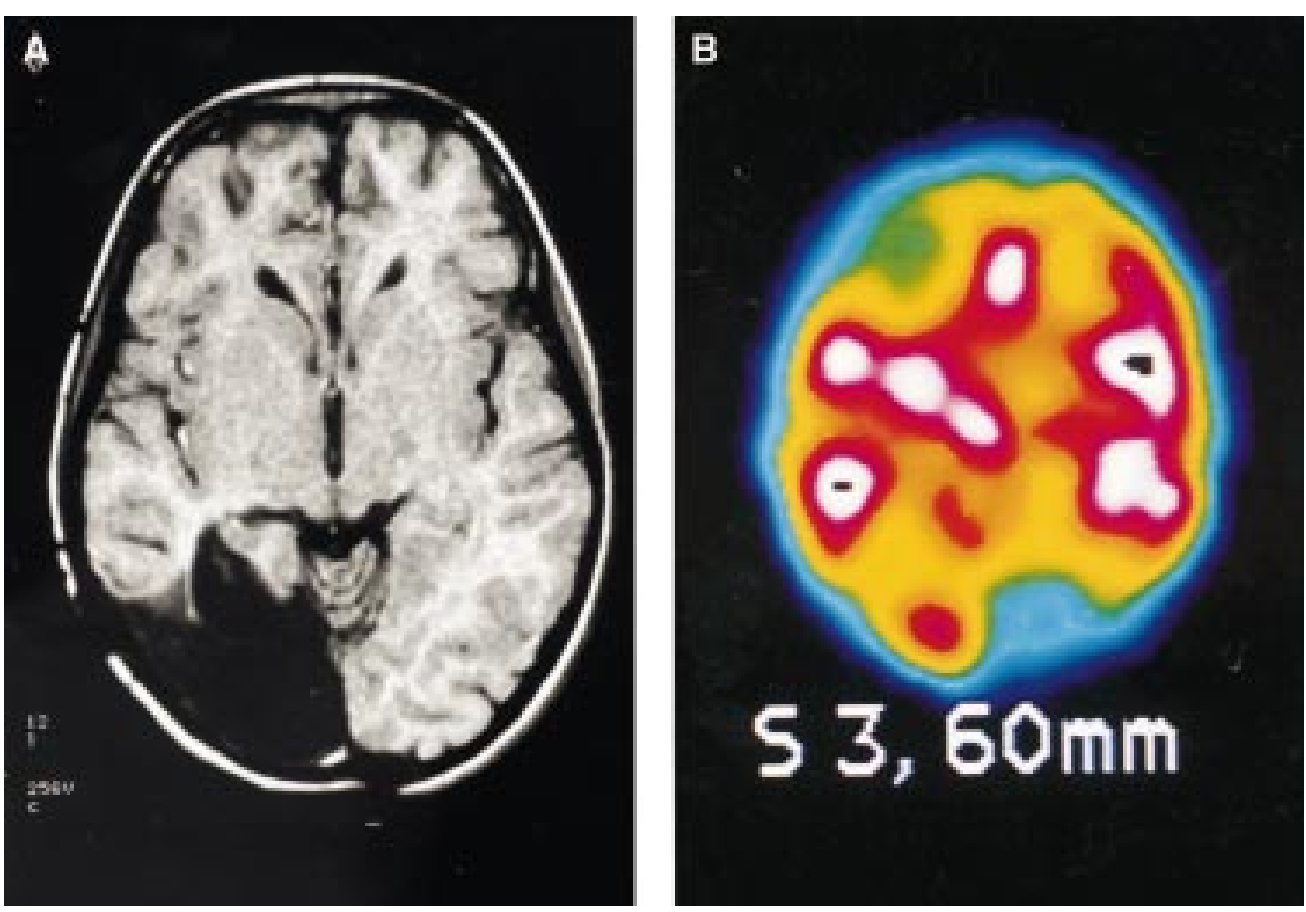

(A) Cerebral MRI shows the postoperative right occipital cavity and an abnormal hyperintensity of the temporal cortex at the junction of the right temporo-occipital sulcus. (B) Single PET shows the right occipital defect and a hypoperfusion in the left frontal cortex on the slice corresponding to the level $+60 \mathrm{~mm}$ above the orbitomeatal line. ${ }^{25}$

chewing. At 3 months of age, the seizures consisted of very brief oculoclonies and occurred one to five times a day. Difficulties following light were noted at 8 months of age. Seizure duration increased progressively from one to two minutes at the age of 18 months and included cyanosis, chewing, breathing irregularities, and tonicoclonic jerks of all four limbs.

Neurological examination disclosed left hemianopsia since the first year of life. At 5 years of age, other neuro-ophtalmological abnormalities included a rotatory nystagmus, a marked myopy of the left eye and a mild myopy of the right eye, a converging strabismus, and a permanent right deviation of gaze. By contrast there was no oculomotor paralysis and fundoscopic examination as well as an electroretinography performed at 5 years of age were normal. Several CT scans and brain MRI at 3, 5, and 6 years of age disclosed nothing atypical. An EEG performed at 4 years of age showed right temporo-occipital discharges during weakness and sleep and secondary diffusion to the frontal lobes. A more precise localisation of the EEG abnormalities was obtained by stereotaxic EEG, which established that the seizures originated in the right calcarine occipital region, but also involved the external part of the right occipital lobe.

A right occipital lobectomy was performed at 7 years of age because of intractable seizures. The occipital cortex was removed including the two edges of calcarine scissure, but the periventricular white matter of the occipital horn was spared. Neuropathological study of the removed occipital lobe showed a characteristic malformative dysplasia. ${ }^{24}$ The seizures stopped immediately after surgery and she remained seizure free for 2 years. At 9 years, she started to develop brief partial complex seizures which were not entirely controlled (two to four seizures a month) with carbamazepine. Her EEG showed slow waves and rare spikes in the right temporal region. Cerebral MRI showed an abnormal hyperintensity of the temporal cortex at the junction of the right temporo-occipital sulcus (figure (A)). This abnormality could reflect a localised cortical dysplasia which was not removed with the surgical intervention or postoperative modification due to the occipital resection itself. At 11 years of age, both single photon emission computed tomography (SPECT) and PET studies $^{25}$ showed a postsurgical right occipital defect, as well as a left frontal hypoperfusion and hypometabolism (figure (B)).

\section{DEVELOPMENT}

The patient has exhibited a mild psychomotor delay since birth. She reached for objects at 7 months, walked at 17 months, and spoke her first words at 24 months. At 4 years of age, she had erratic gaze, often collided with objects, and did not use pointing gestures. The child was unable to recognise people and to show or to name pictures, with the exception of geometric figures and colours. She was able to construct sentences of three to four words, although she did not use pronouns and her language production included stereotyped speech and echolalia. Imaginative play was absent and social interaction was poor, lacking marks of reciprocity such as shared enjoyment or interest in children. Just before surgery, at the age of 7 years, her verbal IQ was 68 on the Wechsler intelligence scale for children-revised (WISC-R). ${ }^{26}$

One year after surgery, there was some improvement in her attentional capacities and social interaction, but her IQ remained stable. 
Table 1 Course of DSM-IV symptoms for diagnosis of autistic disorder according to autism diagnosis interview scores

\begin{tabular}{llc}
\hline DSM-IV items & $4-5 y$ & $13 y$ \\
\hline Social interaction & & \\
Failure to use non-verbal behaviours to regulate social interaction (/6) & 3 & 2 \\
Failure to develop peer relationships (/10) & 6 & 3 \\
Lack of shared enjoyment (/6) & 4 & 1 \\
Lack of socioemotional reciprocity (/10) & 5 & 3 \\
Total (cut off=10) & 18 & 9 \\
Communication & & \\
Delay in spoken language and failure to compensate through gesture (/8) & 4 & 3 \\
Lack of varied spontaneous make believe or social imitative play (/6) & 6 & 4 \\
Relative failure to initiate or sustain conversational interchange (/4) & 2 & 3 \\
Stereotyped, repetitive, or idiosyncratic speech (/8) & 1 & 3 \\
Total (cut off=8) & 13 & 13 \\
Repetitive behaviours and stereotyped patterns & & \\
Encompassing preoccupation or circumscribed pattern of interest (/4) & 4 & 4 \\
Compulsive adherences to non-functional routines or rituals (/4) & 2 & 2 \\
Stereotyped and repetitive motor mannerisms (/2) & 1 & 1 \\
Preoccupation with parts of objects (/2) & 2 & 2 \\
Total (cut off=3) & 9 & 9 \\
\hline
\end{tabular}

*Value above which an area is considered sufficiently impaired for the diagnosis of autism.

Her phonological and syntactic abilities were average for her age, but she continued to show deficits in the communicative use of language and reciprocal interactions. She learned to read and therefore used adaptive behaviour such as shifting the book in front of her eyes. She remained unable to recognise people without hearing their voices. Beginning when she was 8 years old, a restricted interest in schedules and watches pervaded her daily activities, and her routine could not be modified without anxiety reaction. This restricted interest was characterised by repetitive drawings of watches and patches of colour, as well as stereotyped writings of lists of words or sentences.

Due to the influence of the French classification for infant psychopathology, verbal children are rarely diagnosed with autistic disorder in France. As a result, the patient's original diagnosis at 4 years of age was infantile psychosis. Current and retrospective diagnosis of autistic disorder was made at 13 years of age with the use of the ADI-R, ${ }^{27}$ a standardised, in depth interview regarding symptoms associated with autism occurring both in past and present behaviour. This diagnosis was confirmed through clinical examination by one of us (LM). The patient scored higher than the cut off necessary for a diagnosis of autistic disorder in the three relevant areas at the 4 to 5 years of age period. A comparison of her scores for past behaviour ( 4 to 5 years old) with those of her current behaviour shows that she improved in the "social" area but remained clearly above the cut off for autism in the "communication" and the "restricted interest and repetitive behaviours" areas (table). This improvement seems to characterise high functioning persons with autism in general, ${ }^{28}$ and is not restricted to autistic-like syndrome in the context of visual impairment. ${ }^{1416}$

GENERAL COGNITIVE ASSESSMENT

At the age of 13 years, her full scale IQ on the WISC-R fell in the range of mild mental deficiency. ${ }^{26}$ Nevertheless, the cognitive and academic assessment disclosed heterogeneities of performance, with special abilities and specific impairments. She obtained a verbal IQ of 63 (mental age of 8 years 7 months). Her verbal scores were all in the borderline range (information 4, similarities 5, arithmetic 6, vocabulary 4) with the exception of her score on the comprehension subtest (1), on which she exhibited a decline in performance typical of persons with autism. ${ }^{29}$ Her performance IQ was only 45 due to visual impairment (picture completion 3, picture arrangement 1, block design 2, object assembly 1, coding 3). Remarkably, her academic abilities in arithmetic (mental age 10 years 6 months) and spelling and reading (mental age 9 years 11 months) were higher than her intelligence level, both of which are special abilities often encountered in patients with autism. ${ }^{30} 31$

\section{VISUAL AGNOSIA}

The left homonymous hemianopia did not additionally impair her visual performances. She compensated spontaneously her visual field cut by head nodding. Her ability to perceive simple visual features seemed to be average at 13 years of age. She was able to recognise and copy letters, digits, and simple geometric shapes such as triangles, but had difficulties copying geometric shapes of two elements - for example, a square in a circle (mental age 6 years 3 months). Spatial relations were slightly better (mental age 7 years 6 months). ${ }^{32}$ She was unable to perform the simplest object assembly but was able to reproduce some geometric shapes with blocks. ${ }^{26}$ Colour discrimination was preserved.

Face recognition was markedly impaired in her daily life, although she was able to use the hairline as a cue. The patient could recognise family members in photographs but was unable to recognise her own picture. On the Benton facial recognition test ${ }^{33}$ her performance was severely defective (30 of 54, inferior to 6 years). She failed with faces that were oriented differently or under different lighting conditions. In a matching task, she could not distinguish between pictures of faces with different sexes and could only match two out of 10 identical pairs of faces. Face learning was also severely deficient. When asked to identify a set of previously seen unfamiliar faces among new faces, her performance was at the level of chance (on the Rivermead behavioural memory battery's face learning subtest ${ }^{34}$ her score was 0 , three of 10 faces identified correctly, three of 10 false positive). She was also impaired in her ability to recognise emotional expression. A face game showing facial expressions as indicators of feeling created for children aged 4-6 years was employed. She identified smiling as indicative of joy because "the child showed his teeth" but was unable to distinguish between laughing, astonishment, or anger because "the child raised his teeth". In addition, she failed to identify emotional cues based on the appearance of eyes, and was therefore unable to distinguish, for example, between a face that represented sadness and one that was sulky.

Object recognition abilities were also impaired. She successfully named $75 \%$ of a set of line drawings of objects belonging to various categories. ${ }^{35}$ Her performance was $70 \%$ for 
vehicles, $70 \%$ for animals, $70 \%$ for fruits and vegetables, $60 \%$ for body parts, $90 \%$ for clothes, and $90 \%$ for tools. Impairment of object recognition was more evident with overlapping realistic and abstract figures, ${ }^{36}$ and when asked to reconstruct perceptively degraded objects (Kaufman completion test, below the age of 2 years 6 months). ${ }^{37}$ Comparison of small object recognition according to modalities disclosed a slight superiority of the tactile modality $(90 \%)$ over the visual modality $(80 \%)$. She spontaneously explained that she was better in the tactile modality because she did not see the objects. By contrast, she was generally able to define and provide functional information about objects or animals she was unable to recognise. In sum, the patient had an apperceptive visual agnosia which was particularly severe for faces.

MEMORY AND EXECUTIVE FUNCTIONS

The patient's highest score on the WISC-R was the digit span subtest (11, the norm for 14 years, 6 months), although her performance was impaired on digits backward (3, normal mean (SD) 5.9 (1.2)) relative to digits forward (7, normal mean (SD) 4.5 (1.4)). A clear dissociation between forward and backward digit span abilities is indicative of a selective defect of "central executive functions" among otherwise intact working memory. ${ }^{38}$ Her poor performance on the Corsi block test (3, below the norm for 5 years) was reflective of a deficit in visual attention. A computerised memory battery ${ }^{39}$ disclosed above average performance on tests of words and non-word spans, (5 and 4 respectively, the norm for adults). On the California verbal learning test, ${ }^{40}$ she recalled six words on trial 1 and improved to 13 words on trial 5. Her total words recall (trials 1-5) was 49 (mean for 13 years of age). Other scores, including the number of extra list intrusions (0), the semantic cluster (13), the learning of list B (6), and the recall of list A after interference (9) were average for her developmental level. These scores converge with previous findings of generally normal to exceptional list memory in patients with autism. ${ }^{41}$ Nevertheless, many perseverative responses were made by the patient (+3SD).

Numerous tasks tapping executive dysfunction (Wisconsin card sorting test, Tower of London) have poor reliability scores in children under 10 years of age and those with low IQs due to their high level of difficulty. ${ }^{3}$ Furthermore, spatial impairment may affect performance on these tests. As a result, the patient's frontal function was measured using more simplistic tasks. Her performance on the test of word fluency (the norm for 7 years) and the test of sequencing motor response (the norm for 6 years $)^{37}$ was weak. She also showed significant impairment on the trail making test, part B ( -5 SD), an attentional task on which weak performance reflects poor mental flexibility. ${ }^{42}$ She was unable to achieve the simplest maze of the WISC-R, showing a deficit in planning (inferior to 6 years). In sum, the patient's performance was indicative of several executive function impairments, including in- hibition of previously encountered material (perseverations), planning of motor strategies, planning of search strategies in long term memory, and manipulation of information in working memory.

\section{Discussion}

The patient is a child with autistic disorder who presented with developmental visual apperceptive agnosia associated with a right occipitotemporal lesion. In addition, hypometabolism of the left frontal lobe was demonstrated by functional brain imaging in our patient, who also presented an executive deficit. The cognitive deficits and localisation of brain lesions have a likely causal relation with her symptoms of autism.

Although surgery improved control of her seizures, she still had right temporal lobe epilepsy up to the last evaluation. The hypothesis that temporal lobe dysfunction plays a part in autistic disorder was strongly supported by the description of cytoarchitechtonic abnormalities in the limbic structure of patients with autistic disorder ${ }^{43}$ and the finding of unilateral or bilateral complete temporal lobe destruction in a few cases of such patients. ${ }^{44-48}$ Behavioural regression similar to that seen in patients with autistic disorder has also been reported in limbic pathology and epilepsy. ${ }^{49-54}$ Thus, temporal lesions from various aetiologies appear as the most frequent localisation involved in autism. First models of temporal lobe involvement in autism $^{45556}$ propose that early bilateral damage to the medial temporal lobe produces a major amnesic syndrome in adults, which may take the form of severe mental retardation with autistic-like behaviour in children. However, some studies have discarded the hypothesis of an amnesic syndrome in autism, ${ }^{57}$ and recently a few cases of amnesia due to very early hippocampal pathology were reported with relatively preserved cognitive and social development. ${ }^{58}$ The present case suggests that severe dysfunction of the temporo-occipital cortex, rather than the mesial temporal lobe itself, may predispose to the development of autistic disorder.

Even though there are often visual perceptual abnormalities in those with autistic disorder, ${ }^{5-10}$ the relation between developmental visual agnosia and autism remains debated. A retrospective analysis of published cases supports strongly such a relation but only one case with established early temporo-occipital brain lesion has been recently documented..$^{20}$ Autism does not occur, however, when such a lesion occurs later during development. ${ }^{21}$ When present early, visual agnosia, and particularly prosopagnosia, leads to severe impairment which leaves little room for recuperation. ${ }^{59}{ }^{60} \mathrm{It}$ is therefore tempting to link the deficit in interpreting facial cues to the failure to interpret other people's intentions, beliefs, and desires: the "theory of mind". ${ }^{11}$ Visual agnosia for faces may be responsible for many behaviours or absence of behaviours identified as critical symptoms for autistic disorder in the "social" area-for example, absence of emotional reciprocity (absence of direct gaze, limited range of 
facial expressions) and failure to develop peer relationships (lack of interest in children, lack of shared enjoyment, lack of socioemotional reciprocity). On the other hand, an impairment of movement perception may cause lack of pointing and social imitation gestures and failure to use non-verbal behaviours. Central visual impairment supports a model in which restricted interests are directly determined by what it is perceived, the reduction of interest diversity being attributed to the reduction of the visual input. ${ }^{4}$ In this context, the abilities of our patient to recognise and name a restricted range of visual stimuli, specifically colours and simple geometric shapes, might explain her "special interests" for drawing of colour patches and watches. It is, however, likely that early visual agnosia is not sufficient to generate the full range of symptoms of autism. Indeed, persons with autism are shown to present various frontal cognitive deficits, including planning deficit and an inability to switch cognitive programming. ${ }^{62}$ Evidence of frontal brain lesions is, however, rare in autism, and claims of such frontal lobe involvement are generally based on functional studies. ${ }^{16} 63-66$ Hypometabolism of the left frontal lobe was also shown by functional brain imaging in our patient, who exhibited deficits in manipulation of information, verbal fluency, planning, and motor sequencing. The ritualisation of her behaviour and her marked tendency to perseverations was also likely due to frontal dysfunction. ${ }^{3} \mathrm{Al}-$ though we cannot exclude the possibility that autism and visual agnosia were dissociable factors in our patient, our finding raises the intriguing possibility that occipitotemporal lesions may predispose to the development of autism. These lesions are, however, not sufficient to produce by themselves the full range of autistic symptoms. The disconnection from other cortical regions, in particular the frontal lobes, may be crucial in the development of autistic disorder ${ }^{67}$ by disorganising the integrations of cognitive functions.

We thank Patrick Aubourg for his constructive discussion on this case and his work on the manuscript; Sylvie Belleville for her participation to the neuropsychological study, and Beth participation to the
Randolph for editing.

1 Bartak L, Rutter M, Cox A. A comparative study of infantile autism and specific developmental receptive language
disorder. 1. The children. Br f Pychiatry 1975;126:127-45.

2 Baron-Cohen S, Leslie AM, Frith U. Does the autistic child have a "theory of mind"? Cognition 1985;2:37-46.

3 Pennington BF, Ozonoff S. Executive functions and developmental psychopathology. F Child Psychol Psychiatry developmental psy

4 Mottron L, Belleville S. Study of perceptual analysis in high level autistic subject with exceptional graphic abilities. Brain Cogn 1993;23:279-309.

5 Gepner B Mestre D, Masson G, De Schonen S. Postural effects of motion vision in young autistic children. Neuroreport 1995;6:1211-14.

6 Tantam D, Monagham L, Nicholson H, et al. Autistic children's ability to interpret faces: a research note. $f$ Child Psychol Psychiatry 1989;30:623-30.

7 Hobson RP, Ouston J, Lee A. What's in a face? The case of autism. Br F Psychol 1988;79:441-53.

8 Boucher J, Lewis V. Unfamiliar face recognition in relatively able autistic children. $\mathcal{F}$ Child Psychol Psychiatry 1992;33 843-59.

9 Shah A, Frith U. An islet of ability in autistic children: a research note. F Child Psychol Psychiatry 1983;24:613-20.

10 Jolliffe T, Baron-Cohen S. Are people with autism and Asperger syndrome faster than normal on the embedded Asperger syndrome faster than normal on the embed
figures test? F Child Psychol Psychiatry 1997;38:527-34.

11 Young AW, Ellis HD. Visual perception. In: Segalowitz SJ, Rapin I, eds. Handbook of neuropsychology. Vol 7. Child neuropsychology. Amsterdam: Elsevier, 1992:1-14.
12 Brown R, Hobson P, Lee A, et al. Are there "autistic-like" features in congenitally blind children? f Child Psychol Psychiatry $1997 ; 38: 693-703$.

13 Keeler WR. Autistic patterns and defective communication in blind children with retrolental fibroplasia. In: Hoch PH, Zubin J, eds. Psychopathology of communication. New York : Grune and Stratton, 1958:64-84.

14 Goodman R, Ashby L. Delayed visual maturation and autism. Dev Med Child Neurol 1990;32:814-81.

15 Cass H D, Sonksen PM, McConachie HR. Developmental setback in severe visual impairment. Arch Dis Child setback in severe.

16 Jambaqué I, Chiron C, Dulac O, et al. Visual inattention in West syndrome: a neuropsychological and neurofunctional imaging study. Epilepsia 1993;34:692-700.

17 Mc Conachie R. Developmental prosopagnosia: a single case report. Cortex 1976;12:76-82.

18 Kracke I. Developmental prosopagnosia in Asperger's syndrome: presentation and discussion of an individual case. Dev Med Child Neurol 1994;36:873-86.

19 Mottron L, Décarie JC, Mineau S, et al. Overlapping between symptoms of autism and visual agnosia: a case study. Brain Cogn 1996;2:339-41.

20 Mottron L, Mineau S, Décarie JC, et al. Visual agnosia with temporo-occipital brain lesions in an autistic child: a case study. Dev Med Child Neurol 1997;39:699-705.

21 Young AW, Ellis HD. Childhood prosopagnosia. Brain Cogn 1989;9:16-47.

22 De Haan EHF, Campbell R. A 15 year follow up of a case of developmental prosopagnosia. Cortex 1991;27:489-509.

23 Ariel R, Sadeh M. Congenital visual agnosia and prosopagnosia in a child: a case report. Cortex 1996;32:221-40.

24 Taylor DS, Falconer MA, Bruton CJ, et al. Focal dysplasia of the cerebral cortex in epilepsy. $\mathcal{F}$ Neurol Neurosurg Psychiatry 1971;34:369-87.

25 Chiron C, Jambaqué I, Nabbout R, et al. The right brain is dominant in human infants. Brain 1997;120:1057-65.

26 Wechsler D. Echelle d'Intelligence de Wechsler pour Enfants, forme Révisée. Paris: CPA, 1981

27 Rutter M, Le Couteur A, Lord C. Autism diagnosis interview-AR, research. (Traduction française de Plumet MH, Recasens C, Waller D, et al.) Paris: Ed Inserm, 1993.

28 Piven J, Harper J, Palmer P, et al. Course of behavioral change in autism: a retrospective study of high-IQ adolescents and adults. F Am Acad Child Adolesc Psychiatry 1996;35:523-9.

29 Lincoln AJ, Courchesne E, Kilman BA, et al. A study of intellectual abilities in high functioning people with autism. f Autism Dev Disord 1988;18:505-24.

30 Aram DM, Rose DF, Horwitz SJ. Hyperlexia; developmental reading without meaning. In: Malatesha $\mathrm{RN}$, Whitaker HDA, eds. Dyslexia, a global issue. The Hague: Martinus Nijhoff, 1984, 517-31

31 Aram DM, Healy JM. Hyperlexia: a review of extraordinary word recognition. In: Obler $\mathrm{LK}$, Fein D, eds. The exceptional brain: neuropsychology of talent and special abilities. New York: The Guilford Press, 1988:70-102.

32 Hammill DD, Pearson NA, Voress JK. Developmental test of visual perception. Austin: TX Pro-Ed 2e Ed, 1993.

33 Benton AL, de Hamsher K, Varney NR, et al. Facial recognition. Contributions to neuropsychological assesment. New York: tion. Contributions to neuropsychological
Oxford University Press, 1983:30-43.

34 Wilson B, Cockburn J, Baddeley AD. The Rivermead behavioural memory test manual. Suffolk: Thames Valley Test Company, 1985.

35 Snoodgrass JG, Vanderwatt M. A standardized set of 260 pictures: norms for name agreement, image agreement, familiarity and visual complexity. Fournal of Experimental Psychology Human Learning and Memory 1980;6:174-215.

36 Agniel A, Joanette Y, Doyon B, et al. Protocole MontréalToulouse d'Evaluation des Gnosies Visuelles. Paris: Ortho Edi-
tion, 1993 .

37 Kaufman AS, Kaufman NL. Batterie pour l'examen psychologique de l'enfant. K-ABC. Paris, ECPA, 1993.

38 Bender MB. Defect in reversal of serial order of symbols. Neuropsychologia 1979;17:125-38.

39 Chatelois J, Pineau H, Belleville S, et al. Batterie informatisée de l'évaluation de la mémoire inspirée de l'approche cognitive. Canadian Psychology 1993;34:45-53.

40 Delis CD, Kramer JH, Kaplan E, et al. California verbal learning test. San Antonio: The Psychological Corporation, 1987.

41 Minshew NJ, Goldstein G, Taylor G, et al. Academic achievement in high functioning individuals. 7 Clin Exp Neuropsychol 1994;16:261-70.

42 Reitan RM. Trail making test results for normal and braindamaged children. Percept Mot Skills 1971;33:575-81.

43 Bauman ML, Kemper TL. Limbic and cerebellar abnormalities: consistant finding in early infantile autism. $\mathcal{F}$ Clin Exp Neuropsychol 1988;47:369.

44 Ghaziuddin M, Tsai LY, Eilers L, et al. Brief report: autism and herpes simplex encephalitis. F Autism Dev Disord 1992; 22:107-13.

45 DeLong GR, Bean SC, Brown FR. Acquired reversible autistic syndrome in acute encephalopathic illness in children. Arch Neurol 1981;38:191-4.

46 Gillberg C. Onset at age 14 of a typical autistic syndrome. A case report of a girl with Herpes simplex encephalitis. $\mathcal{F}$ Autism Dev Disord 1986;16:369-75.

47 Gillberg IC. Autistic syndrome with onset at age 31 years: Herpes encephalitis as a possible model for childhood autism. Dev Med Child Neurol 1991;33:912-29. 
48 Hoon AH, Reiss AL. The mesial-temporal lobe and autism: Case report and review. Dev Med Child Neurol 1992;34: Case rep

49 Bolton PF, Griffiths PD. Association of tuberous sclerosis of temporal lobes with autism and atypical autism. Lancet 1997;349:392-5.

50 Gonzales RC, Welsh JT, Sepulveda AC. Autismo en la esclerosis tuberosa. Gaceta Med Mexico 1994;130:374-9.

51 Curatolo P, Cusmai R, Cortesi F, et al. Neuropsychiatric aspects of tuberous sclerosis. Ann New York Acad Sci 1991; 615:8-16.

52 Deonna T, Ziegler AL, Moura-Serra J, et al. Autistic regression in relation to limbic pathology and epilepsy: report of two cases. Dev Med Child Neurol 1993;35:166-76.

53 Chugani HT, Da Silva E, Chugani DC. Infantile spasms: III. Prognostic implications of bitemporal hypometabolism on positron emission tomography. Ann Neurol 1996;39:643-9.

54 DeLong G, Heinz ER. The clinical syndrome of early-life bilateral hippocampal sclerosis. Ann Neurol 1997;42:11-17.

55 Bachevalier J. An animal model for childhood autism: memory loss and socioemotional disturbances following neonatal damage to the limbic system in monkey. In: Tamminga NA, Schultz SC, eds. Advances in neuropsychiatry and minga NA, Schultz SC, eds. Advances in neuropsychiatry and psychopharmacology
Raven, 1991:129-40.

56 Bachevalier J. Medial temporal lobe structures and autism: a review of clinical and experimental findings. Neuropsychologia 1994;32:627-48.

57 Bowler DM, Matthews NJ. Asperger's syndrome and memory: similarity to autism but not amnesia. Neuropsychologia 1997;35:65-70.
58 Vargha-Khadem F, Gadian DG, Watkins KE, et al. Differential effects of early hippocampal pathology on episodic and semantic memory. Science 1997;277:376-80.

59 Mancini J, de Schonen S, Deruelle C, et al. Face recognition in children with early right or left brain damage. Dev Med Child Neurol 1994;36:156-66.

60 Schiavetto A, Décarie JC, Flessas J, et al. Childhood visual agnosia: a seven-year follow-up. Neurocase 1997;3:1-17.

61 Baron-Cohen S, Wheelwright S, Joliffe T. Is there a language of the eyes ? Evidence from normal adults, and adults with Autism and Asperger syndrome. Visual Cognition 1997;4: 311-31.

62 Stuss DT, Shallice T, Alexander MP, et al. A multidisciplinary approach to anterior attentional functions. Ann N Y Acad Sci 1995;769:191-211.

63 Horwitz B, Rumsey J, Grady C, et al. Interregional correlations of glucose utilization among brain regions in autistic adults. Ann Neurol 1987;22:118.

64 Jambaqué I, Cusmai R, Curatolo P, et al. Neuropsychological aspects of tuberous sclerosis in relation to epilepsy and MRI findings. Dev Med Child Neurol 1991;33:698-705.

65 Georges MS, Costa DC, Kouris K, et al. Cerebral blood flow abnormalities in adults with infantile autism. 7 Nerv Ment Dis 1992;180:413-17.

66 Zibolvicius M, Garreau B, Samson Y, et al. Delayed maturation of the frontal cortex in childhood autism. Am f Psychiatry 1995;152:248-52.

67 Damasio AR, Maurer RG. A neurological model for childhood autism. Arch Neurol 1978;35:77-86. 